LUCAS FABER DE ALMEIDA ROSA

\title{
PARÂMETROS DE INTERPRETAÇÃO DAS LIMITAÇÕES MATERIAIS AO PODER DE REFORMA DA CONSTITUIÇÃO
}

Dissertação de Mestrado

Orientador: Professor Doutor Roger Stiefelmann Leal

UNIVERSIDADE DE SÃO PAULO

FACULDADE DE DIREITO

São Paulo - SP

2018 


\section{PARÂMETROS DE INTERPRETAÇÃO DAS LIMITAÇÕES MATERIAIS AO PODER DE REFORMA DA CONSTITUIÇÃO}

Dissertação de Mestrado, apresentada a Banca Examinadora do Programa de Pós-Graduação em Direito, da Faculdade de Direito da Universidade de São Paulo, na área de concentração de Direito do Estado, sob a orientação do Professor Doutor Roger Stiefelmann Leal.

UNIVERSIDADE DE SÃO PAULO

FACULDADE DE DIREITO

São Paulo - SP 2018 


\section{AGRADECIMENTOS}

Em primeiro lugar, agradeço a Deus, inteligência suprema, causa primária de todas as coisas.

À Isabella, meu amor, agradeço imensamente por todo o apoio, paciência e parceria; por caminhar ao meu lado para juntos vencermos mais um desafio.

Ao meu pai, à minha mãe e aos meus irmãos, agradeço por constituírem - ontem, hoje e sempre - os alicerces de carinho e felicidade da minha vida.

Ao meu orientador, Professor Roger Stiefelmann Leal, agradeço por todo o apoio concedido à minha pesquisa. A sua orientação minuciosa e rigorosa foi fundamental para a conclusão do trabalho.

Devo agradecer também a Rodrigo Mudrovitsch, grande incentivador dessa empreitada acadêmica e amparo essencial para que ela fosse concluída com êxito.

Agradeço, ainda, aos meus amigos Michel Yamashita, Lucas Santos, Júlio Leão, Leonardo Leite Chaves, Alexandre Vitorino Silva, Luís Belém, Paulo Timponi Torrent, Mário Henrique Ditticio, Rafael Ferreira, Pedro Júlio Sales D’Araújo, Alexandre Freire, Luís Felipe Alves e Gustavo Teixeira Gonet Branco pela colaboração inestimável.

Por fim, agradeço à Faculdade de Direito da Universidade de São Paulo pelo espaço concedido ao meu trabalho de pesquisa. 


\section{RESUMO}

ROSA, Lucas Faber de Almeida. Parâmetros de interpretação das limitações materiais ao poder de reforma da Constituição. 2018. 159 páginas. Mestrado Faculdade de Direito, Universidade de São Paulo, São Paulo, 2018.

A principal finalidade da presente dissertação é identificar parâmetros interpretativos das cláusulas pétreas, contribuindo para 0 debate desses relevantes mecanismos constitucionais. Não se pretende fixar regras abstratas de interpretação para jurisdição constitucional, mas, sim, estabelecer referenciais aptos a, de um lado, fornecer critérios para abordagem do caso concreto e, por outro, municiar a comunidade jurídica de ferramental para examinar criticamente a judicialização do processo de construção constitucional. Para tanto, são analisadas as teorias elaboradas até o momento pelos juristas, problematizando não apenas o alcance conferido por cada uma às cláusulas pétreas, mas também os pressupostos reproduzidos pela doutrina a respeito do tema. Com efeito, são revisitados dois pressupostos largamente adotados sobretudo por interpretações expansivas das cláusulas pétreas: (i) a concepção de que as limitações materiais ao poder de reforma se colocam como postulados abstratos, adotados em momento de deliberação superior; e (ii) a percepção de que a jurisdição constitucional é instituição capaz de ser condutora primordial do processo de reforma, potencializada pela adoção de interpretação principiológica das cláusulas pétreas. A crítica desses pressupostos desvela a nuance institucional das cláusulas pétreas, exigindo que a análise de sua extensão interpretativa passe pela reflexão sobre a repercussão no processo de construção constitucional. A partir dessa premissa, as teorias da interpretação das cláusulas pétreas são revisitadas com o objetivo de estabelecer parâmetros interpretativos condizentes com o texto constitucional. Nesse contexto, interpretações ampliativas das cláusulas pétreas são naturalmente abordadas com maior ceticismo. Contudo, mesmo as teorias restritivas impõem cuidado metodológico mais apurado do jurista. Não basta afirmar a necessidade de interpretar as limitações materiais de forma restritiva, ante suposto déficit democrático do Poder Judiciário, sem considerar que os dispositivos petrificados efetivamente têm papel importante a 
desempenhar no sistema constitucional. Simplesmente articular com a necessidade de restringir o alcance das cláusulas pétreas pode igualmente significar casuísmo da jurisdição constitucional, especialmente quando seus integrantes encontram respaldo ideológico na coalizão nacional dominante e pretendem facilitar movimentos de alteração constitucional. Com base nesses pressupostos, a dissertação avança para propor parâmetros interpretativos dos limites materiais à reforma a partir dos seguintes referenciais: os limites textuais; a expressão "tendente a abolir" prevista no $\S 4^{\circ}$ do art. 60 da Constituição Federal; e os imperativos sistêmicos. Sustenta-se que a redação das limitações materiais deve ser o ponto de partida e de chegada da respectiva interpretação, sendo impróprio abandonar o texto para buscar em valores morais a resposta adequada ao problema posto. $\mathrm{O}$ argumento central será desenvolvido no sentido de que 0 intérprete deve adotar como centro de gravidade a literalidade dos preceitos em jogo, norteada pela expressão "tendente a abolir". Por isso, não é qualquer modificação constitucional que merece a reprimenda jurisdicional. Defende-se também que o alcance das limitações materiais deve ser perscrutado a partir da noção de sistema jurídico, presente a insuficiência do método exegético. Não se trata de buscar valores ou princípios intrínsecos à Lei Maior, mas, sim, de identificar no funcionamento do sistema constitucional o sentido atribuível aos conceitos elencados no art. $60, \S 4^{\circ}$, da Constituição Federal.

Palavras-chave: jurisdição constitucional; cláusulas pétreas; reforma constitucional; hermenêutica constitucional; processo constituinte; democracia. 


\section{ABSTRACT}

ROSA, Lucas Faber de Almeida Rosa. Interpretation parameters of the material limits to constitutional amendment. 2018. 159 pages. Master Faculty of Law, University of São Paulo, São Paulo, 2018.

The main purpose of this thesis is to identify interpretation parameters to material limits of constitutional reform, contributing to the debate of these relevant constitutional mechanisms. The thesis does not intend to fix abstract rules to judicial review, but to provide references to the analysis of constitutional amendments. Thus, the theories elaborated so far by the jurists are analyzed, problematizing not only the scope conferred by each one to the material limits of reform, but also the presuppositions reproduced by the doctrine. In fact, two assumptions largely adopted by expansive interpretations of the material limits are revisited: (i) the conception that material limitations on the power of reform are considered abstract postulates, adopted in a superior deliberation; and (ii) the perception that judicial review is an institution capable of being protagonist of constitutional reform, enhanced by the adoption of a principiological interpretation of material limits. The critique of these premises reveals the institutional nuance of material limits, requiring that the analysis of their interpretive extension pass through reflection on the repercussion in the process of constitutional construction. From this premises, theories of interpretation of material limits are revisited in order to establish interpretive parameters consistent with Constitution. In this context, expansive interpretations of material limites are naturally approached with greater skepticism. However, even restrictive theories impose more precise methodological care. It is not enough to affirm the need to interpret material limitations in a restrictive manner, given the supposed democratic deficit of judicial branch, without considering that material limits effectively have an important role to play in the constitutional system. Simply articulating with the need to restrict the scope of material limits can also mean a casuist judicial review, especially when its members find ideological support in the dominant national coalition and intend to facilitate constitutional change movements. Based on these assumptions, the thesis advances to propose interpretive parameters of material limits based on the 
following references: the textual limits of Constitution and systemic imperatives. It is argued that the text of material limits must be the starting point and the point of arrival of interpretation, and it is inappropriate to abandon the text to seek in moral values the adequate response to the problem posed. The central argument will be developed in the sense that the interpreter should adopt as a center of gravity the literality of the precepts at stake, guided by the expression "tending to abolish", listed in art. 60, § 4으, of the Brazilian Federal Constitution. Therefore, it is not any constitutional change that must be nullified by the judicial branch. It is also argued that the scope of material limits must be examined from the notion of legal system, given the insufficiency of the exegetical method.

Keywords: judicial review; constitutional amendment; constitutional interpretation; constituent process; democracy. 


\section{SUMÁRIO}

INTRODUÇÃO

CAPÍTULO 1 - LIMITAÇÕES MATERIAIS AO PODER DE REFORMA E SUA INTERPRETAÇÃO

1.1 Limitações materiais ao poder de reforma: noções gerais .................................................. 15

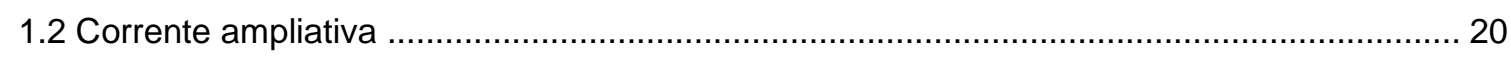

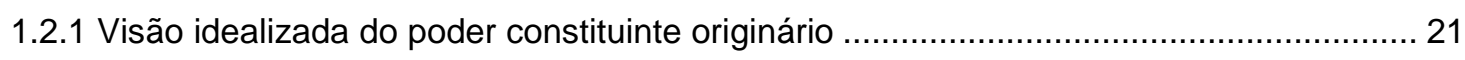

1.2.2 Desconforto com a alteração da Constituição ............................................................... 26

1.2.3 Confiança na capacidade de o Poder Judiciário proteger e incrementar o projeto constitucional delineado no momento fundacional ................................................................. 28

1.2.4 Interpretação principiológica das limitações materiais ao poder de reforma .................. 34

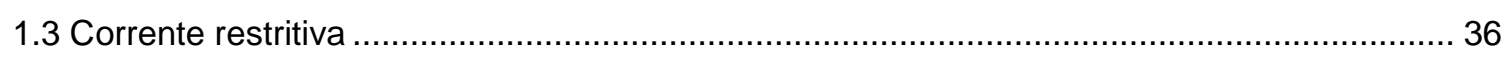

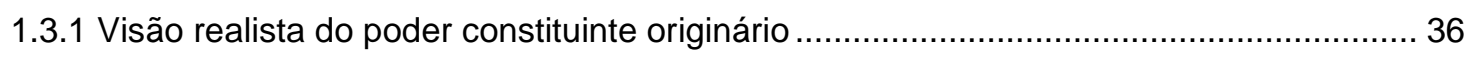

1.3.2 Compreensão da necessidade de alteração da Constituição .......................................... 38

1.3.3 Desconfiança da legitimidade democrática do Poder Judiciário para operar como

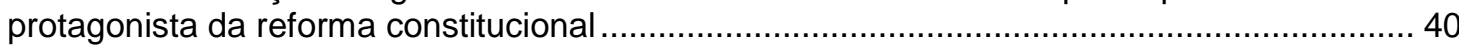

1.3.4 Rejeição da abordagem principiológica das limitações materiais ao poder de reforma . 42

CAPÍTULO 2 - LIMITAÇÕES MATERIAIS AO PODER DE REFORMA: CARACTERÍSTICAS E

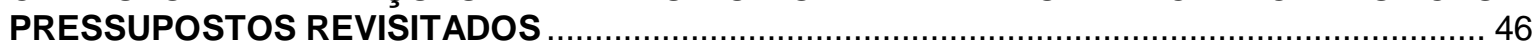

2.1 Cláusulas pétreas e a contigencialidade dos processos de transição política ....................... 46

2.1.1 Transitologia política e superconstitucionalidade ........................................................... 46

2.2.2 O processo de transição política do Leste Europeu ........................................................... 50

2.2.3 As condições reais de deliberação e as cláusulas pétreas ........................................... 57

2.2 A mudança é a regra: implicações institucionais da inserção do Poder Judiciário como última

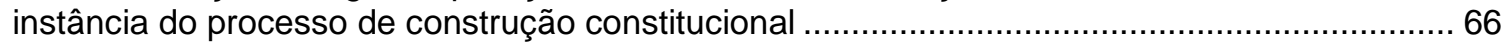

2.2.1 Cláusulas pétreas como mecanismos de deslocamento institucional. .............................67 67

2.2.2 Jurisdição constitucional e cláusulas pétreas: implicações institucionais. ....................... 71

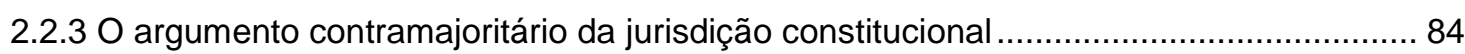

2.3 A necessária diferenciação metodológica do controle de constitucionalidade de Emenda... 88

2.4 Interpretação extensiva ou restritiva? O casuísmo na interpretação das limitações materiais

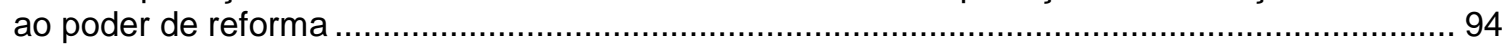

CAPÍTULO 3 - PARÂMETROS PARA A INTERPRETAÇÃO DAS LIMITAÇÕES MATERIAIS AO

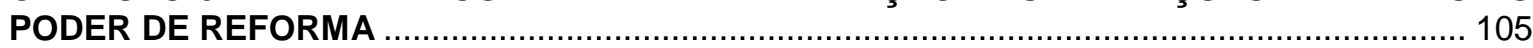

3.1 Horizonte textual das limitações materiais ao poder de reforma ...................................... 105

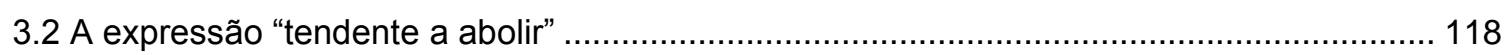

3.3 Limitações materiais ao poder de reforma e o sistema constitucional................................ 127

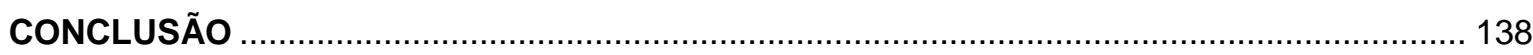

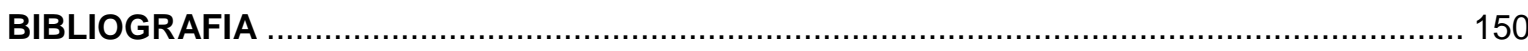




\section{INTRODUÇÃO}

Quando as cláusulas pétreas são inseridas no debate público, aos interlocutores imediatamente surge a imagem do núcleo intangível da Constituição, que não pode ser alcançado sequer por debates parlamentares conduzidos no âmbito do processo constitucional qualificado de reforma. De fato, não é raro observar na cena política brasileira agentes políticos invocando as cláusulas pétreas como limites a mudanças institucionais e, até mesmo, à própria discussão no seio da comunidade.

Nessa linha, as cláusulas pétreas buscam fundamento no intento do poder constituinte originário impor limites éticos e substanciais além dos quais seu próprio projeto de nação seria desnaturado'. A geração que elaborou a Constituição como lei suprema da sociedade, com pretensão de eternização, vincula as demais em seus fundamentos mais caros, impedindo que deliberações dos poderes constituídos rompam com a própria essência do texto constitucional. Sob esse ângulo, as cláusulas pétreas assegurariam que o processo de construção constitucional siga determinadas balizas que impeçam qualquer regressão na comunidade 2 .

No Brasil, a consagração das cláusulas pétreas em sucessivos textos constitucionais consolidou o entendimento de que elas são juridicamente vinculantes e parâmetros para o controle de constitucionalidade de emendas à Carta Federal ${ }^{3}$. Nessa linha, o elenco de cláusulas pétreas no art. $60, \S 4^{a}$, da Constituição ${ }^{4}$, o Supremo Tribunal Federal consolidou a possibilidade de controle

\footnotetext{
${ }^{1}$ Oscar Vilhena Vieira define o fenômeno da superconstitucionalidade, expresso nas cláusulas pétreas, como "processo de substantivação do direito constitucional, passando a legitimidade da produção legislativa, assim como a da reforma da Constituição, a estar vinculadas não somente à realização de um procedimento, mas à submissão a um Direito com conteúdo ético, que busca seu fundamento nos direitos humanos, no direito natural e nos princípios do Estado de Direito e da separação dos Poderes" ( $A$ Constituição e sua reserva de justiça (um ensaio sobre os limites materiais ao poder de reforma). São Paulo: Malheiros, 2009. p.25-26.)

2 Nesse sentido: HOLMES, Stephen. Precommitment and the paradox of democracy. In: Constitutionalism and Democracy. Editado por Jon Elster e Rune Slagstad. Cambridge: Cambridge University Press, 2003. P. 240.

${ }^{3}$ SARMENTO, Daniel; SOUZA NETO, Cláudio Pereira de. Os direitos fundamentais e o poder de reforma constitucional. In: Direitos fundamentais e jurisdição constitucional. CLĖVE, Clèmerson Merlin; FREIRE, Alexandre (org.). São Paulo: Editora Revista dos Tribunais, 2014. P. 273-274.

${ }^{4} \S 4$ \% Não será objeto de deliberação a proposta de emenda tendente a abolir:

I - a forma federativa de Estado;

II - o voto direto, secreto, universal e periódico;
} 
das emendas constitucionais ${ }^{5}$. Desde então, a Corte declarou a inconstitucionalidade de inúmeras emendas constitucionais, intervindo em vasta gama de temas, desde reformas previdenciárias até alterações no regime de precatórios.

Assim, o Supremo tem recorrentemente manuseado as cláusulas pétreas e participado do processo de construção constitucional. A par da elaboração de justificativas teóricas para a existência e legitimidade democrática das cláusulas pétreas, que permeiam grande parte da doutrina, não são poucas as perplexidades que envolvem a interpretação dessa espécie normativa. A extensão que deve ser conferida às cláusulas pétreas e o papel interpretativo desempenhado pelo Poder Judiciário convergem para a elaboração das seguintes perguntas: como devem ser interpretadas as limitações materiais ao poder de reforma? É pertinente a interpretação ampliativa das cláusulas pétreas?

A doutrina se divide na tentativa de responder a essa espécie de questionamento. Existem, de um lado, teorias que buscam ampliar o alcance das cláusulas pétreas, partindo, ora de sua classificação como princípios, ora da identificação de pressupostos normativos abstratos para o regular funcionamento do regime democrático, não raro extraídos das teorias da justiça.

Por outro lado, autores defendem interpretação restritiva das limitações materiais ao poder de reforma, com abordagem realista do momento fundacional, partindo da premissa de que a mudança é a regra do processo de construção constitucional. Além disso, essa corrente não vislumbra na jurisdição constitucional ator institucional apto a desempenhar papel protagonista na

III - a separação dos Poderes;

IV - os direitos e garantias individuais.

${ }^{5}$ Neste ponto, não é possível mencionar a possibilidade de controle de constitucionalidade de emendas constitucionais sem fazer referência à obra de Otto Bachof, denominada "Normas constitucionais inconstitucionais?". Ao abordar o tema a princípio paradoxal, Bachof sustentou a possibilidade de inconstitucionalidade de normas constitucionais inseridas pelo poder constituinte derivado, abordando expressamente o tema das cláusulas pétreas: "Uma lei de alteração da Constituição (isto é, na medida em que se trate da Lei Fundamental, uma lei de alteração do texto da Constituição: art. 79, n. I) pode infringir, formal ou materialmente, disposições da Constituição formal. Dá-se o primeiro caso, quando são observadas as disposições processuais prescritas para a alteração da Constituição; ocorre o último, quando uma lei se propõe alterar disposições da Constituição contrariamente à declaração de imodificabilidade destas inserta no documento constitucional: assim, por exemplo, uma lei de alteração da Lei Fundamental que, contra o disposto no art. 79, n. 3, eliminasse a articulação da Federação em Estados federados ou princípio da participação destes na legislação, ou lesasse os princípios assentes nos arts. I e 20. Não é necessário mostrar mais pormenorizadamente que a lei de alteração, embora sendo ela própria uma norma constitucional formal, seria, num como no outro caso, inconstitucional" (BACHOF, Otto. Normas constitucionais inconstitucionais. Coimbra: Almedina, 2007. P. 52). 
reforma da Constituição, tampouco identifica na teoria dos princípios solução adequada para a interpretação das limitações materiais ao poder de reforma.

No entanto - e neste ponto reside o problema a ser enfrentado na dissertação -, as propostas de interpretação das cláusulas pétreas, ora restritivas, ora ampliativas, têm se mostrado incapazes de captar plenamente o fenômeno da superconstitucionalidade e de fornecer parâmetros adequados para a abordagem jurisdicional das cláusulas pétreas. Não viabilizam, portanto, o próprio controle da atuação do Poder Judiciário nesse mister constitucional.

O debate se desenvolve em torno de posições concernentes à ampliação ou à restrição do alcance das cláusulas pétreas, sem se refletir sobre parâmetros para essa atividade interpretativa, com reflexos importantes na jurisdição constitucional. No julgamento da ação direta de inconstitucionalidade n. 4357, o Supremo examinou os dispositivos da emenda constitucional no 62/2009, que alteraram o regime de precatórios, declarando a inconstitucionalidade material do artigo 100, $2^{\circ}$, da Carta Federal, que limita a preferência no pagamento àqueles com sessenta anos de idade completos à época da expedição do precatório. Consignou-se que esse balizamento temporal afronta a isonomia, porquanto pretere aqueles que preencherem o requisito objetivo enquanto ainda pendente $o$ pagamento. $\mathrm{O}$ mesmo parâmetro foi manejado como fundamento para assentar a inconstitucionalidade da compensação de precatórios com débitos do respectivo credor com a Fazenda Pública. O Supremo concluiu ainda que a atualização monetária prevista na emenda afronta o direito de propriedade, tendo em vista que o índice oficial de remuneração da caderneta de poupança é insuficiente para mensurar a variação do poder aquisitivo da moeda.

O Tribunal abordou a controvérsia em jogo a partir de parâmetros idênticos aos processos objetivos nos quais o objeto é ato normativo infraconstitucional. Não foi discutida a intensidade da contrariedade à cláusula pétrea ensejadora da intervenção judicial, tampouco foi analisada qual a extensão dos direitos e garantias individuais petrificados. Em outras palavras, o Supremo interviu no processo de reforma da Constituição sem balizas claras, decidindo questão que se encontra na periferia das limitações materiais ao poder de reforma.

O objetivo da dissertação, portanto, é identificar parâmetros interpretativos das cláusulas pétreas, contribuindo para o debate desses relevantes mecanismos constitucionais. Não se pretende fixar regras abstratas de interpretação para o 
Supremo Tribunal Federal, mas sim estabelecer referenciais aptos a, de um lado, fornecer critérios para abordagem do caso concreto e, por outro, municiar a comunidade jurídica de ferramental para examinar criticamente a judicialização do processo de construção constitucional. Para tanto, será necessário analisar as teorias oferecidas até o momento pelos juristas, problematizando não apenas o alcance conferido por cada uma às cláusulas pétreas, mas também os pressupostos reproduzidos pela doutrina a respeito do tema.

Sob esse ângulo, será necessário revisitar dois pressupostos largamente adotados pela corrente ampliativa no que tange ao tema das cláusulas pétreas: (i) a concepção de que as limitações materiais ao poder de reforma se colocam como postulados abstratos, adotados em momento de deliberação superior; e (ii) a percepção de que a jurisdição constitucional é instituição capaz de ser condutora primordial do processo de reforma, potencializada pela adoção de interpretação principiológica das cláusulas pétreas.

A crítica desses pressupostos desvelará a nuance institucional e contingencial das cláusulas pétreas, exigindo que a análise de sua extensão interpretativa passe pela reflexão sobre a repercussão no processo de construção constitucional. A partir dessa premissa, as teorias da interpretação das cláusulas pétreas serão revisitadas com o objetivo de estabelecer parâmetros interpretativos condizentes com o texto constitucional.

Nesse contexto, interpretações ampliativas das cláusulas pétreas serão naturalmente abordadas com maior ceticismo. Contudo, mesmo as teorias restritivas impõem cuidado metodológico mais apurado do jurista. Não basta afirmar a necessidade de interpretar as limitações materiais de forma restritiva, ante suposto déficit democrático do Poder Judiciário, sem considerar que os dispositivos petrificados efetivamente têm papel importante a desempenhar no sistema constitucional. Simplesmente articular com a necessidade de restringir o alcance das cláusulas pétreas pode igualmente significar casuísmo da jurisdição constitucional, especialmente quando seus integrantes encontram respaldo ideológico na coalizão nacional dominante e pretendem facilitar movimentos de alteração constitucional. É necessária, assim, investigação voltada a estabelecer referenciais para interpretação das limitações materiais ao poder de reforma, consentâneos com as repercussões sistêmicas desse instituto. 
Eis, portanto, a empreitada proposta: efetuar releitura crítica da visão ampliativa das cláusulas pétreas para, a partir dela, estabelecer parâmetros interpretativos das limitações materiais ao poder de reforma.

A própria definição do problema em jogo revela os limites da reflexão a ser realizada. Propõe-se a identificação de parâmetros interpretativos das limitações materiais ao poder de reforma explicitamente previstas no art. $60, \S 4^{\circ}$, da Constituição Federal. A revisitação crítica de premissas adotadas na leitura das cláusulas pétreas contribuirá também, embora lateralmente, para a abordagem de temas como os atinentes à existência de limites implícitos ao poder de reforma, à possibilidade de dupla revisão e à compreensão dos obstáculos formais ao poder de reforma. Contudo, essas questões não são objeto deste trabalho.

Para alcançar os objetivos propostos, esta dissertação será desdobrada em três partes. No Capítulo 1, serão apresentadas as principais teorias da interpretação, a partir da identificação das principais características das correntes ampliativa e restritiva. Esses marcos teóricos serão objeto de releitura crítica no Capítulo 2, no qual as premissas atinentes ao momento fundacional e ao papel da jurisdição constitucional serão problematizados, assim como a ambiguidade metodológica e o casuísmo decorrentes do atual cenário interpretativo.

No Capítulo 3, serão propostos, a partir das reflexões estabelecidas nas seções anteriores acerca das limitações materiais do poder de reforma, suas repercussões institucionais no processo de construção constitucional brasileiro e as atuais teorias da interpretação, parâmetros para interpretação das limitações materiais ao poder de reforma previstas no art. 60 , $\S 4^{\circ}$, da Constituição Federal.

De início, será afastada a viabilidade da interpretação extensiva das limitações materiais, considerada a releitura crítica, sob o prisma institucional, realizada no Capítulo 2. Contudo, o afastamento da abordagem ampliativa não desborda na automática adoção da interpretação restritiva, porquanto esta também pressupõe critérios hermenêuticos. Assim, após essa reflexão, o estudo avançará no sentido de fixar os parâmetros para a interpretação das cláusulas pétreas, os quais serão desenvolvidos a partir do seguinte tripé: (i) os limites textuais; (ii) a expressão "tendente a abolir"; e (iii) os imperativos sistêmicos.

Será demonstrado que a redação das limitações materiais deve ser o ponto de partida e de chegada da respectiva interpretação. É impróprio, como em regra procedem os adeptos do neoconstitucionalismo, abandonar o texto para buscar 
em valores morais a resposta adequada ao problema posto. $\mathrm{O}$ argumento central será desenvolvido no sentido de que o intérprete deve adotar como centro de gravidade a literalidade dos preceitos em jogo, norteada pela expressão "tendente a abolir". Por isso, não é qualquer modificação constitucional que merece a reprimenda jurisdicional.

A par desse binômio, será sustentado que o alcance das limitações materiais deve ser perscrutado a partir da noção de sistema jurídico, presente a insuficiência do método exegético. Não se trata de buscar valores ou princípios intrínsecos à Lei Maior, mas, sim, de identificar no funcionamento do sistema constitucional o sentido atribuível aos conceitos elencados no art. 60, $§ 4^{\circ}$, da Constituição Federal. Nesse sentido, será defendido que, ao lado dos elementos textuais, o sentido das limitações materiais decorre também de imposições sistêmicas que conformam os conceitos jurídicos em jogo. Essa investigação sistêmica deve refutar a busca por princípios implícitos ou valores superconstitucionais - como aqueles advindos da teoria da justiça -, identificando os nexos funcionais no próprio desenvolvimento do direito positivo. 


\section{CONCLUSÃO}

Ao longo do presente trabalho foram elencadas as conclusões parciais das reflexões operadas em cada capítulo, de modo a encadear as ideias e relações causais concernentes ao tema. Nada obstante, persiste a necessidade de delinear e retomar os principais conceitos e ideias que se pretendeu aprofundar e esclarecer na execução da pesquisa em tela.

(l)

A análise das limitações materiais ao poder de reforma evidenciou a existência de duas correntes interpretativas contrapostas: a ampliativa e a restritiva. Os pressupostos identificados nessas abordagens não são uniformemente adotados por todos os autor enquadráveis em cada corrente, mas possibilitaram a visualização do quadro interpretativo preponderante na doutrina atinente às cláusulas pétreas.

A corrente restritiva aceita com naturalidade processos de reforma constitucional, não apresentando visão idealizada do momento fundacional. Compreende o processo constituinte como algo histórico, sujeito a restrições cognitivas e obstáculos negociais. Não confere à jurisdição constitucional importância ímpar, tampouco a vê como instituição essencial ao processo de construção constitucional. Essa corrente não equipara as limitações materiais ao poder de reforma a princípios constitucionais, entendendo serem distintos os conteúdos protegidos, por exemplo, pela separação de poderes-cláusula pétrea e pelo princípio da separação de poderes.

A corrente ampliativa, por sua vez, revela compreensão idealizada do poder constituinte originário, visto como momento de deliberação superior, no qual a comunidade reunida estabelece racionalmente as balizas que nortearão o desenvolvimento da sociedade. Apresenta, consequentemente, desconforto com a alteração da Constituição, sustentando a necessidade de ter-se o projeto constituinte defendido e potencializado. Há inequívoca desconfiança em relação ao poder constituinte derivado, inversamente proporcional à confiança depositada na capacidade de o Poder Judiciário proteger e incrementar o projeto constitucional delineado no momento fundacional. É pautada também pela 
interpretação principiológica das limitações materiais ao poder de reforma, responsáveis justamente por operacionalizar a expansão do seu alcance. Isso porque a compreensão das cláusulas pétreas como princípios e, consequentemente, mandamentos de otimização, conduz à aplicação dessas normas na maior medida possível.

(II)

O estudo das características das correntes interpretativas evidenciou que a premissa da corrente ampliativa relativa à visão idealizada do processo constituinte é equivocada e insuficiente para a adequada compreensão das limitações materiais ao poder de reforma. A transitologia política, concentrada neste trabalho no estudo de caso de países do leste europeu, revela a contingencialidade do processo constituinte, o qual não é pautado por condições ideais de deliberação. As inúmeras variáveis e assimetrias de força nas negociações afastam a compreensão de ter-se o momento de fundação constitucional como eminentemente superior e racional. Existe cálculo político, a partir das expectativas futuras dos atores, inclusive na elaboração de normas constitucionais, aspecto revelado pela inserção, na Constituição de 1988, de amplo espectro de matérias.

Paralelamente, a perspectiva idealista e metafísica surge contrastante com a própria análise do papel da Constituição, como unidade normativa intocável, em sociedades complexas, sob o ângulo do constitucionalismo supranacional. Com efeito, restou demonstrado que o congelamento de momento fundacional superior é incoerente com a necessidade, verificada nas sociedades contemporâneas, de constante reconstrução de narrativas capazes de atender à pluralidade de grupos, crenças, ideologias e ordens jurídicas. O próprio conceito de unidade da Constituição é questionado em prol de documento aberto, constantemente construído e redimensionado por um emaranhado de comunidades, entes e instâncias políticas, muitas vezes transnacionais.

A compreensão das dificuldades enfrentadas por cidadãos em momentos de transição política, complementada pelos aportes advindos do constitucionalismo supranacional, inviabiliza soluções interpretativas que resultem no engessamento permanente de dispositivos constitucionais moldados sob 
contingências político-econômicas. Ademais, o afastamento do momento fundacional como cenário argumentativo ideal implode concepções ampliativas das cláusulas pétreas, como se ao Judiciário coubesse corrigir as vicissitudes do processo legislativo que também se encontravam presentes na deliberação das clausulas pétreas.

Restou demonstrado que a contigencialidade do processo de transição política impõe que as limitações materiais ao poder de reforma constituem mecanismo direcionado a conferir equilíbrio à evolução político-normativa da comunidade. Antes de qualquer referência a princípios éticos abstratos voltados à concretização de cenário normativo ideal, as cláusulas pétreas são aqueles pontos que sobressaíram como centrais do compromisso entre as partes deliberantes na Assembleia Constituinte.

O abandono da concepção ideal de deliberação usualmente imputada às cláusulas pétreas reforça a necessidade de valorizar a democracia como experimento e rechaça a adoção de arranjos institucionais que engessem 0 sistema constitucional e fechem os canais de mudança política - como ocorre com o estabelecimento do controle jurisdicional de constitucionalidade das emendas, transformando os tribunais em artífices supremos do processo de construção constitucional.

(III)

A análise da jurisdição constitucional revelou que o protagonismo que the é atribuído pela corrente ampliativa esbarra em importantes limitações institucionais e democráticas. Isso não implica seja refutado o controle judicial de emendas, tampouco pressupõe a superação ou abandono do debate em torno da interpretação propriamente dita dos textos petrificados. Contudo, quando determinadas abordagens interpretativas desbordam os limites textuais e sistêmicos das limitações materiais ao poder de reforma, tácita ou explicitamente admitindo a jurisdição constitucional como elemento decisivo no processo de construção constitucional, as reflexões em torno dos limites e possibilidades da atuação judicial na reforma tornam-se relevantes. 
Nesse contexto, constatou-se que as dificuldades em coletar e interpretar dados atinentes a problemas constitucionais complexos, aliadas à formação do jurista, carente de interdisciplinaridade, implicam em contribuição limitada, muitas vezes deficitária da jurisdição constitucional para o debate público. Além disso, a linguagem própria do discurso jurídico, inalcançável para grande parte da população, obstrui movimentos de mudança da Carta, confinando as possibilidades de rearranjo institucional nos estreitos limites e legitimidade do raciocínio jurídico. A esse fato se soma a reduzida accountability do Judiciário, que se mostra incapaz de dialogar abertamente com a sociedade civil, com a assunção dos ônus inerentes à efetiva inserção no debate político da comunidade.

Ademais, restou demonstrado que a jurisdição constitucional apresenta significativas dificuldades para exercer papel efetivamente contramajoritário. A jurisdição constitucional tem sua composição definida pela coalizão política dominante, de modo que os Tribunais tendem a ser contramajoritários justamente quando seus membros ainda não se adequaram ao novo arranjo das forças políticas. Fora dessas situações, a jurisdição constitucional tende a racionalizar e legitimar os projetos hegemônicos na classe política. A par desse aspecto, 0 próprio Judiciário é estruturado de forma incompatível com a função de enfrentamento de movimentos majoritários, porquanto a própria implementação da decisões judiciais pressupõe, ao fim e ao cabo, a participação de outros Poderes.

No caso brasileiro, constitui pressuposto básico da atuação do Supremo na reforma constitucional a contrariedade a cláusula pétrea prevista no art. 60 , §

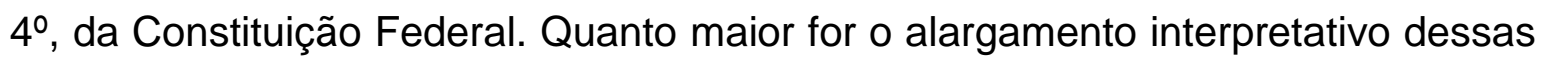
normas, mais amplo será o campo reservado ao Judiciário no processo de construção constitucional. A compreensão das limitações institucionais da jurisdição constitucional recomenda a rejeição de tais interpretações ampliativas, considerada a possibilidade de ter-se órgão dessa natureza no vórtice da reforma constitucional. 
Para além das premissas teóricas revisitadas ao longo da dissertação, a análise das correntes interpretativas das limitações materiais ao poder de reforma revelou equivocada aproximação metodológica entre os controles de constitucionalidade de Emenda e de lei, verificada também na jurisprudência do Supremo Tribunal Federal. É dizer, quando analisada situação na qual alegada a inconstitucionalidade de Emenda, o intérprete procede a exame idêntico àquele que realizaria se enfrentasse a alegação de desarmonia, com a Constituição Federal, de lei ordinária.

Não se perquire da intensidade diferenciada necessária para declaração de inconstitucionalidade de Emenda, considerada a expressão "tendente a abolir". Olvida-se que não é qualquer impacto na norma petrificada que implica a inconstitucionalidade da reforma, mas, sim, aquele que conduza à abolição do preceito. Além disso, ignora-se que a extensão da limitação material ao poder de reforma não equivale a todas as normas que a conformam constitucionalmente. Apenas os preceitos reveladores do conteúdo essencial são petrificados. Por isso, a alusão ao pacto federativo-cláusula pétrea, por exemplo, não pode ser confundida com todos as normas constitucionais de distribuição de atribuições entre os diferentes entes federados.

A corrente ampliativa apresenta dois aspectos que contribuem para formação desse quadro. A potencialização do engessamento constitucional como pressuposto dessa abordagem, a partir de compreensão idealizada do momento constituinte e de desconforto com a mudança constitucional, conduz à extensão do conteúdo petrificado a normas apenas marginalmente relacionadas ao postulado qualificado como cláusula pétrea.

A par desse aspecto, a adoção de interpretação principiológica das limitações materiais ao poder de reforma conduz à confusão entre a norma petrificada e o princípio constitucional correlato. A locução "separação de poderes", prevista no art. 60, $\S 4^{\circ}$, da Constituição Federal, passa a ser tratada como sinônimo do princípio da separação de poderes, ensejando o tratamento metodológico idêntico aos controles de constitucionalidade de lei e Emenda. Esse método de trabalho inclui a utilização indevida de instrumentos típicos da análise principiológica, como a máxima da proporcionalidade, para solução de problemas atinentes às limitações materiais ao poder de reforma. Além disso, a abordagem principiológica, baseada na concepção de princípios como mandamentos de 
optimização, aplicados de forma mais ampla possível, na medida das possibilidades fáticas e jurídicas, contribui para a não consideração de balizas textuais explícitas das cláusulas pétreas, como a expressão "tendente a abolir".

O cenário interpretativo das limitações materiais ao poder de reforma evidenciou também a dificuldade de fornecimento de parâmetros hermenêuticos para a jurisdição constitucional, bem assim para a análise adequada das decisões judiciais sobre o tema. A corrente restritiva, embora seja consistente no reconhecimento das implicações institucionais das cláusulas pétreas, tem dificuldade em evidenciar parâmetros interpretativos ao jurista. Articula-se com as limitações do Judiciário, incumbindo-Ihe de tutelar apenas o conteúdo essencial das cláusulas pétreas. Contudo, a ausência de definição do que seria o aspecto essencial dessas normas abre campo para a discricionariedade do magistrado. A corrente ampliativa afirma a necessidade de ampliar o alcance das limitações com base em leitura principiológica; sem, porém, atentar para as balizas textuais e para as próprias peculiaridades da aplicação das cláusulas pétreas. Trabalha-se com noções vagas, como a ponderação de princípios ou o núcleo essencial das garantias, para defender, a depender do caso concreto, postura deferente ou ativista da jurisdição constitucional.

Essa ausência de critérios resulta em ambiguidades dentro das próprias correntes doutrinárias. Elival da Silva Ramos, embora apresente pressupostos atinentes à teoria restritiva, defende a expansão da locução "direitos e garantias individuais" para alcançar todos os direitos fundamentais. Oscar Vilhena Vieira, malgrado defenda a ampliação do alcance do limite material relativo ao voto, sustenta a restrição da cláusula pétrea atinente à forma federativa de Estado.

A análise da jurisprudência do Supremo Tribunal Federal também revelou significativa dubiedade e oscilação nas soluções conferidas aos casos, sem justificativa teórica para o tratamento distinto de cada situação. O Tribunal tende a expandir o alcance dos limites materiais ao poder de reforma da Constituição relativos aos direitos e garantias individuais, rechaçando emendas que apenas afetem esses preceitos, enquanto reformas constitucionais atinentes à forma 
federativa de Estado e à separação de poderes são objeto de menor ingerência da jurisdição constitucional.

O campo interpretativo - tanto na academia quanto no Judiciário - é, portanto, casuísta. Articula-se ciclicamente com a restrição ou ampliação das cláusulas pétreas, bem assim com o contraponto entre democracia e direitos fundamentais, em debate estéril que não resulta na identificação de parâmetros interpretativos para os limites materiais à reforma. A ressaltar essa óptica, identificou-se ao longo da dissertação que as abordagens que mais avançaram no sentido de fornecer balizas objetivas para a interpretação foram as de Oscar Vilhena Vieira, Yaniv Roznai e Elival da Silva Ramos, que não se limitaram a afirmar ser necessária abordagem restritiva ou ampliativa.

A desconstrução dos pressupostos da corrente ampliativa das cláusulas pétreas atinentes ao processo constituinte idealizado e ao papel desempenhado pela jurisdição constitucional, descortinaram o horizonte textual como primeiro parâmetro interpretativo das limitações materiais ao poder de reforma. Demonstrou-se que o texto das cláusulas pétreas, tal como redigido pelo Constituinte, revela o compromisso possível entre as partes conflitantes em processo deliberativo árduo e não integralmente racional. Superá-lo ao argumento de ter-se as balizas de uma comunidade ideal ou a potencialização de princípios abstratamente deduzidos significa erodir o próprio edifício sobre o qual a sociedade encontrou a legitimidade. O desbordamento da referência literal implica verdadeiro contrassenso, porquanto a partir do objetivo de tutelar o projeto constitucional inaugural, impõe-se à sociedade, usualmente a partir da jurisdição constitucional, identidade engessada, alheia ao que deliberado no momento fundacional.

O abandono dos limites impostos pelo texto constitucional também mostrou-se impróprio porque implica o protagonismo da jurisdição constitucional ou, quando menos, a ampliação de sua atuação. Como visto ao longo desta dissertação, são diversas as limitações institucionais e reduzida a legitimidade democrática do Judiciário, as quais não justificam sua transformação - mediante interpretação ampliativa -, de participante excepcional do processo de reforma 
constitucional, em artífice principal do desenvolvimento do projeto inaugurado pelo Constituinte.

A centralidade do texto petrificado no processo interpretativo revelou-se importante sobretudo para a compreensão da limitação material à reforma relativa ao "voto direto, secreto, universal e periódico". A observância do horizonte textual afasta interpretações que equivalem essa cláusula pétrea ao princípio democrático, expandindo-a para alcançar regras estruturantes do processo político. O preceito estabelece como patamar mínimo da democracia brasileira o sistema representativo, a alternância de poder, a liberdade do eleitor e a universalidade dos eleitores. Arranjos institucionais fora desse espectro não se encontram engessados. Essa leitura é compatível inclusive com o momento histórico vivido na Assembleia Constituinte, em que surgia essencial cristalizar a noção do voto após duas décadas de regime autoritário.

O mesmo ocorre no tocante aos "direitos e garantias individuais". A atenção à literalidade da norma revela o contexto do processo constituinte, em que a espinha dorsal do projeto inaugurado girava em torno de assegurar liberdades individuais após anos de repressão pelo aparato estatal. Por isso, são inadequadas leituras que, a partir de argumento contrafactual, defendem que os direitos sociais são cláusulas pétreas porque consistem em elementos essenciais do projeto constitucional ou desempenham papel importante na concretização de determinado princípio de justiça. $O$ texto das limitações materiais revela o projeto real da Assembleia Constituinte, e não abstração acadêmica que proponha a espinha dorsal ideal da Constituição.

Restou demonstrado também que a restrição da cláusula pétrea em tela aos direitos e garantias individuais não consubstancia deslize do Constituinte. Embora tenha fortalecido o aspecto social do Estado brasileiro, a Constituição oscila entre a ingerência mínima e a maior intervenção estatal, transparecendo a fratura ideológica da Constituinte sobre o tema. A decisão sobre o viés não era, portanto, nuance consolidada da essência do projeto constitucional. Pelo contrário, o debate permaneceu aberto às gerações futuras, culminando no recalibramento do Estado Social em diversas emendas constitucionais.

O entendimento de não serem os direitos sociais cláusulas pétreas não implica conferir-Ihes caráter programático ou diminuir sua importância como fator assecuratório da dignidade da pessoa humana. As limitações materiais ao poder 
de reforma não estão à disposição do intérprete para a construção de sistema ideal, nem mesmo servem à operacionalização da tutela desse ou daquele direito. As cláusulas pétreas têm função própria, relacionada à estabilização do sistema em torno de dispositivos considerados fundantes pelo Constituinte.

(VII)

O segundo parâmetro interpretativo das limitações materiais ao poder de reforma proposto nesta dissertação consiste na expressão "tendente a abolir", prevista no $\S 4^{\circ}$ do art. 60 da Constituição Federal. Demonstrou-se que 0 destinatário principal desse comando constitucional é o Congresso Nacional. Isso porque o dispositivo é voltado a regular o processo legislativo, e não o controle judicial de constitucionalidade de emendas, cuja operacionalização no Brasil decorre de interpretação sistemática realizada pelo Supremo Tribunal Federal.

Essa inversão na análise do preceito permite concluir que a expressão "tendente a abolir" não objetiva suavizar a rigidez do verbo "abolir", impedindo reformas que apenas afetem os limites materiais à reforma; mas, sim, foi construída dessa forma porquanto relativa ao processo legislativo. Ou seja, a proposta de emenda é tendente a abolir porque apenas a emenda efetivamente promulgada pode implicar a exclusão de determinada norma petrificada. A expressão "tendente" revela o momento deliberativo a que se refere a proibição e não a intensidade em que as limitações materiais podem ser afetadas. É necessário, portanto, abandonar concepção segundo a qual, no exame de constitucionalidade de emenda, a locução "tendente" prepondera sobre o verbo "abolir".

Abolir, por sua vez, não significa afetar ou atingir. A intervenção na cláusula pétrea, pelo poder constituinte derivado, para ser proibitiva, deve ser severa a ponto de desnaturar o limite estabelecido pelo Constituinte. O verbo "abolir" consiste, portanto, em importante marco diferenciador dos controles de constitucionalidade de emenda e de lei. Não é qualquer contrariedade a preceito petrificado que implica a inconstitucionalidade de emenda. O conteúdo essencial da norma em tela deve ser desnaturado, de forma semelhante ao que preconiza o Tribunal Constitucional alemão mediante a aplicação da teoria do abandono fundamental. 
Mostra-se imprópria também a utilização da máxima da proporcionalidade para definição do que se entende do conteúdo essencial dos limites materiais a ser preservado. Esse método foi elaborado para resolver conflitos em direitos fundamentais, averiguando a adequação dos meios escolhidos e a necessidade da medida para proteção de determinado direito em detrimento de outro atinente a indivíduos ou grupos diversos. Não é disso que tratam as cláusulas pétreas, cujo exercício interpretativo impõe que o intérprete identifique o seu conteúdo essencial, e não a adequação ou necessidade de determinada medida do poder público ou mesmo da atuação de particulares.

(VIII)

O terceiro parâmetro interpretativo proposto nesta dissertação refere-se às imposições sistêmicas que conformam as limitações materiais ao poder de reforma. Essa abordagem desdobrou-se em dois eixos complementares: (i) a Constituição como sistema de direito positivo e (ii) a identificação de cada cláusula pétrea como sistema a ser preservado em si.

O primeiro eixo aprofunda a observância do horizonte textual das cláusulas pétreas para preconizar que o sentido e a essencialidade desses preceitos devem ser extraídos, sob a óptica positivista, dos nexos funcionais da própria Constituição, e não de modelos metafísicos alheios ao texto constitucional.

No segundo eixo, foi proposta, na esteira das reflexões de Elival da Silva Ramos, a análise das limitações materiais ao poder de reforma em etapas, considerando cada cláusula pétrea um sistema de proteção em si, cujas nuances e características podem ser alterados sem necessariamente desnaturar o todo que o Constituinte pretendeu proteger.

No tocante aos direitos e garantias individuais, a análise foi desdobrada em duas etapas. Na primeira, o intérprete deve identificar a posição ocupada pelo direito individual afetado no sistema de garantias fundamentais. Direitos periféricos podem ser mais atingidos por reformas constitucionais do que direitos individuais centrais para o sistema, como o direito à vida, à liberdade, à igualdade, e à propriedade. Essa perspectiva permite que cada direito tenha efeito 
bloqueador compatível com o sistema protetivo da Constituição de 1988, evitando o engessamento desmedido de direitos secundários.

Na segunda etapa, a análise refere-se ao subsistema de tutela do direito individual específico. Identifica-se, por exemplo, no sistema pétreo relativo ao direito de propriedade, os aspectos essenciais e aqueles laterais ou marginais. Esse momento analítico permite a distinção entre determinado direito individual enquanto limite material à reforma e as normas constitucionais conformadoras desse direito. Propicia, ainda, a delimitação do conteúdo essencial, a partir da compreensão da existência de características sem as quais a norma petrificada se mantém.

Esse método sistêmico foi transposto para as demais limitações materiais ao poder de reforma, sem, contudo, a segregação em duas etapas. A forma federativa de Estado, quando vislumbrada como sistema, revela que é possível alterar o regime de competências - legislativas, tributárias e administrativas - dos entes federados sem abolir essa cláusula pétrea. A partir dessa abordagem, a imunidade tributária, potencializada pelo Supremo Tribunal Federal no exame da ação direta de inconstitucionalidade o 926, relator o ministro Sydney Sanches, pode ser recalibrada e excepcionada sem abolir a federação, ainda que implique a diminuição de receitas de determinados entes federados.

Em síntese, compreender cada limitação material como sistema, e não como princípio, viabiliza a melhor compatibilização desses preceitos com os pressupostos das cláusulas pétreas, possibilitando o desenvolvimento de metodologia própria de análise da constitucionalidade de emendas, condizente com os referenciais fornecidos pelo próprio texto constitucional.

Os parâmetros interpretativos propostos nessa dissertação não são exaurientes e tampouco pretendem solucionar, aprioristicamente, as controvérsias que inevitavelmente serão submetidas à jurisdição constitucional. Há um longo caminho a ser trilhado pelos juristas no sentido de compreender adequadamente esses mecanismos de estabilização constitucional, no contexto do naturalmente longo e demorado processo de amadurecimento democrático da sociedade.

Contudo, a leitura sistemática fornece balizas alinhadas com as condições reais de deliberação constituinte e com as próprias limitações institucionais e democráticas da jurisdição constitucional. O Poder Judiciário inevitavelmente participará de momentos sensíveis e dramáticos da construção do projeto 
constitucional brasileiro, mas tal intervenção deve ocorrer de forma coerente e deferente em relação ao que definido nas instâncias representativas da sociedade. 


\section{BIBLIOGRAFIA}

ABRAMOVICH, Victor; COURTIS, Christian. Los derechos sociales como derechos exigibles. Madrid: Trotta, 2002.

ACKERMANN, Bruce. Nós o povo soberano: fundamentos do direito constitucional. Belo Horizonte: Del Rey, 2006.

. The new separation of powers. In Harvard Law Review, vol. 113, n. 3, jan. 2000.

ALBERT, Richard. Constitutional Handcuffs. Arizona State Law Journal 42, (2010): 663-.

ALEXY, Robert. Teoria dos Direitos Fundamentais. São Paulo: Malheiros, 2008.

- Teoria da argumentação jurídica: a teoria do discurso racional como teoria da justificação jurídica. Trad. Zilda Hutchinson Schild Silva. São Paulo: Landy, 2008.

. Constitucionalismo Discursivo. Trad.: Luis Afonso Heck. Porto Alegre:

Livraria do Advogado Editora, 2007.

ANDRADE, Fábio Martins. As cláusulas pétreas como instrumentos de proteção dos direitos fundamentais. In: Revista de Informação Legislativa. Brasília, ano 46, n. 181, jan./mar. 2009.

ANDRADE, José Maria Arruda de. Hermenêutica jurídica e a questão da textura aberta. In: Revista Brasileira de Filosofia 2009 - RBF 233.

ARANHA, Márcio lorio. Conteúdo essencial das cláusulas pétreas. In: Revista Notícia do Direito Brasileiro 7: 389-402, 2000.

ARATO, Andrew. Civil Society, Constitution, and Legitimacy. Nova York: Rowman \& Littlefield Publishers, 2000.

ASH, Timothy Garton. Nós, o povo: a revolução de 1989 em Varsóvia, Budapeste, Berlim e Praga. São Paulo: Companhia das Letras, 1990.

ATRIA, Fernando. Existem direitos sociais? In: Revista do Ministério Público do Rio Grande do Sul. Livraria do Advogado, n 56, set.-dez./2005, p. 9-46.

BACHOF, Otto. Normas constitucionais inconstitucionais. Coimbra: Almedina, 2007.

BACHOUR, Samir Dib. Poder Constituinte Derivado de Equivalência às Emendas Constitucionais. Dissertação de Mestrado submetida ao Departamento de Direito Faculdade de Direito da Universidade de São Paulo. São Paulo: 2014. 
BALKIN, Jack; LEVINSON, Sanford. The processes of constitutional change: from partisan entrenchment to the national surveillance state. Fordham Law Review, Vol. 75, No. 2, 2006.

BALKIN, Jack. Living originalism. Cambridge: The Belknap Press of Harvard University Press, 2011.

. The Roots of the Living Constitution (May 1, 2012). Boston University Law Review, Vol. 92, 2012; Yale Law School, Public Law Working Paper No. 249. BARROSO, Luís Roberto. Neoconstitucionalismo e Constitucionalização do Direito (O Triunfo Tardio do Direito Constitucional no Brasil). Rio de Janeiro: Lumen Juris, 2007.

- O controle de constitucionalidade no direito brasileiro: exposição sistemática da doutrina e análise crítica da jurisprudência. 2ª $2^{\text {a }}$ ed. São Paulo: Saraiva, 2006.

BERNAL, Carlos. Unconstitutional Constitutional Amendments in the case Study of Colombia: An analysis of the Justification and Meaning of the Constitutional Replacement Doctrine. International Journal of Constitutional Law. Volume 11 Issue 2. April/2013, P. 339-357.

BONAVIDES, Paulo. Curso de Direito Constitucional. Malheiros: São Paulo, 2013. BRANDÃO, Rodrigo. Mecanismos de diálogos constitucionais nos EUA e no Brasil. In: SARMENTO, Daniel (coordenador). Jurisdição constitucional e política. Rio de Janeiro: Forense, 2015.

. São os direitos sociais cláusulas pétreas? Em que medida? In: Revista Eletrônica Custo Legis. Volume 2 - 2010.

BRITTO, Carlos Ayres. A Constituição e os limites de sua reforma. In: Revista Latino-Americana de Estudos Constitucionais. Editora Del Rey, oㅡ 1, jan./jun. 2003.

CANOTILHO, J. J. Gomes. Direito Constitucional e teoria da Constituição. $2^{\underline{a}}$ ed., Coimbra: Almedina, 1998.

CARTER, Stephen L. "Do Courts Matter?" (1992). Michigan Law Review. Volume 90. 1992. P. 1216-1224.

COELHO, Inocêncio Mártires. A Forma Federativa de Estado Como Cláusula Pétrea: uma Abordagem Hermenêutica. DPU N. 29 - Set-Out/2009 - Estudos Jurídicos. 
COUTO, Cláudio G.; ARANTES, Rogério B. Constituição, governo e democracia no Brasil. Revista Brasileira de Ciências Sociais. São Paulo, v. 21, n. 61.

DAHL, Robert A. Decision-making in a democracy: the Supreme Court as a national policy-maker. In: 6 J. Pub. L. 2791957.

. On democracy. New Haven: Yale University Press, 2000.

. Polyarchy: Participation and Opposition. New Haven: Yale University Press, 1971.

DWORKIN, Ronald. O império do direito. 3. Edição. São Paulo: Martins Fontes, 2014.

ELSTER, Jon (org.). Constitutionalism and Democracy. Cambridge: Cambridge University Press, 1988.

. Ulysses and the Sirens: Studies in Rationality and Irrationality. Cambridge: Cambridge University Press, 1984.

- Ulisses Liberto: estudos sobre racionalidade, pré-compromisso e restrições. São Paulo: Editora UNESP, 2009.

. Constitution-making in eastern europe: rebuilding the boat in the open sea. In: Public Administration Vol. 71 Spring/Summer. 1993.

. Forces and mechanisms in the constitution-making process. Duke Law Journal. Vol. 45:364. 1995.

ELY, John Hart. Democracy and Distrust: A Theory of Judicial Review. Harvard University Press, 1980.

FERRAZ JÚNIOR, Tércio Sampaio. "O Judiciário frente à divisão dos Poderes: um princípio em decadência?" Revista da USP, São Paulo, n. 21, 1994.

FERREIRA FILHO, Manoel Gonçalves. Curso de direito constitucional. 30 ed. rev. atual. São Paulo: Saraiva, 2003.

. O Poder Constituinte. 3a ed. São Paulo: Saraiva, 1999.

. "O papel político do judiciário na ordem constitucional vigente". In: Revista do Advogado. São Paulo: Associação dos Advogados de São Paulo, set.2008.

. Sete vezes democracia. São Paulo: Convívio, 1977.

. Significação e alcance das "cláusulas pétreas". Revista de Direito Administrativo. Rio de Janeiro, 202: 11-17, out./dez/ 1995.

GARGARELLA, Roberto. As teorias da justiça depois de Rawls: um breve manual de filosofia política. São Paulo: WWF Martins Fontes, 2008. 
GODOY, Miguel Gualano. Devolver a Constituição ao Povo - Crítica à supremacia judicial e diálogos institucionais. Fórum: Belo Horizonte, 2017.

HAMILTON, Alexander; MADISON, James; JAY, John. The Federalist. New York: Metro Books, 2002.

HAYEK, Frederick. The Constitution of Liberty. Chicago: University of Chicago Press, 1960.

HIRSCHL, Ran. The Judicialization of Mega-Politics and the Rise of Political Courts. In: Annual Review of Political Science, Vol. 11, 2008.

HOLMES, Stephen; SUNSTEIN, Cass. The cost of rights: why liberty depends on taxes. New York: W. W. Norton \& Companny, 2005.

JUNQUEIRA, Maria Olívia Pessoni. Discurso e Política Constitucional: A reforma constitucional na doutrina brasileira da Primeira República. Dissertação de Mestrado submetida ao Departamento de Direito Faculdade de Direito da Universidade de São Paulo. São Paulo: 2015.

KAUFMANN, Rodrigo de Oliveira. Direitos Humanos, Direito Constitucional e Neopragmatismo. Repositório de teses da Universidade de Brasília. 2010.

KMIEC, Keenan D. "The origin and current meanings of "judicial activism". In California Law Review, 2004, vol. 92, pp. 1441-1477.

KNIGHT, Jack. Institutionalizing Constitutional Interpretation. In: Ferejohn, J.; Rakove, J.; RILEY, J. (org.). Constitutional Culture and Democratic Rule. Cambridge University Press.

LARENZ, Karl. Metodologia da Ciência do Direito. Lisboa: Fundação Calouste Gulbenkian, 1969.

LEAL, Roger Stiefelmann. Pluralismo, políticas públicas e a Constituição de 1988: considerações sobre a práxis constitucional brasileira 20 anos depois. In: MORAES, Alexandre (coordenador). Os 20 anos da Constituição da República Federativa do Brasil. São Paulo, Atlas, 2009.

. Direitos sociais e a vulgarização da noção de direitos fundamentais. Disponível em: < http://www6.ufrgs.br/ppgd/doutrina/leal2.htm >. Acesso em 20 de abril de 2016.

LEITE, Fábio Carvalho. Revisão da doutrina dos limites ao poder de reforma na constituição de 1988 (reflexões a partir do estudo de dois casos). Direito, Estado e Sociedade. Volume 9 - oㅜ 29. jul/dez 2006. P 87 a 151. 
LEMIEUX, Scott; WATKINS, David. Beyond the 'Countermajoritarian Difficulty': Lessons from Contemporary Democratic Theory. In: Polity Volume 41, N. 1, Janeiro de 2009.

LEVINSON, Daryl J. \& PILDES, Richard H.. Separation of Parties, not Powers. Harvard Law Review, Vol. 119, n. 8, June 2006, pp. 2311-2386.

LOEWENSTEIN, Karl. Teoria de la Constitución. $2^{2}$ ed. esp. Trad. Alfredo Gallego Anabitarte. Barcelona: Ariel, 1986.

LOUIS Michael Seidman. "The secret life of the political questions doctrine". In: The John Marshall Law Review, ㄲo 37, 2004.

MACHADO, Hugo de Brito. Curso de Direito Tributário. São Paulo: Malheiros, 2011.

MAIOLINO, Eurico Zecchin. Limitações ao Poder de Reforma Constitucional na Constituição Federal de 1988. Dissertação de Mestrado submetida ao Departamento de Direito Faculdade de Direito da Universidade de São Paulo. São Paulo: 2011.

MAUS, Ingborg. Judiciário como superego da sociedade - o papel da atividade jurisdicional na "sociedade órfã". In: Novos Estudos no 58 - novembro de 2000. MELO, Marcus André. Mudança constitucional no Brasil: dos debates sobre regras de emendamento na constituinte à "megapolítica". In: Novos Estudos no 97, novembro de 2013, p. 187-206.

MENDES, Conrado Hübner. Direitos Fundamentais, Separação de Poderes e Deliberação. São Paulo: Saraiva, 2011.

- Reforma do Estado e Agências Reguladoras: Estabelecendo os Parâmetros de discussão. In: Direito Administrativo Econômico, Malheiros, 2000, Sundfeld, Carlos Ari (Coordenador).

. Controle de Constitucionalidade e Democracia. Rio de Janeiro: Elsevier, 2008.

MENDES, Gilmar Ferreira; BRANCO, Paulo Gustavo Gonet. Curso de direito constitucional. São Paulo: Saraiva, 2011.

. Cláusulas pétreas ou garantias constitucionais?. Revista Consulex, Ano I,

n. 12, Dezembro/1997.

MOREIRA, Eduardo Ribeiro. Teoria da reforma constitucional. São Paulo: Saraiva, 2012. 
; FRÓES, Rodrigo Dias Rodrigues de Mendonça. É desejável a participação popular nas reformas constitucionais?. Revista Brasileira de Estudos Constitucionais. ano 10 - n. 34. janeiro/abril de 2016. p. 183-207.

MUDROVITSCH, Rodrigo de Bittencourt. Desentrincheiramento da jurisdição constitucional. São Paulo: Saraiva, 2014.

. Democracia e Governo Representativo. Tese de Doutorado submetida ao Departamento de Direito Faculdade de Direito da Universidade de São Paulo. São Paulo: 2016.

. ; ROSA, Lucas Faber de Almeida. Processos de Mutação Constitucional e "Framework Originalism". In: Revista Jurídica Consulex. Ano XVII. Número 389. P. 20-22.

NETO, José Duarte. Rigidez e Estabilidade Constitucional - Estudo da Organização Constitucional Brasileira. Tese de Doutorado submetida ao Departamento de Direito Faculdade de Direito da Universidade de São Paulo. São Paulo: 2009.

NEVES, Marcelo. Entre Têmis e Leviatã: uma relação difícil. 3 edição. São Paulo: Editora WMF Martins Fontes, 2012.

O'DONNELL, Guillermo Alberto; SCHMITTER, Philippe C. Transições do regime autoritário: primeiras conclusões. São Paulo: Editora Revista dos Tribunais, 1988.

PASSOS, J. J. Calmon de. A Constitucionalização dos Direitos Sociais. Revista Eletrônica sobre a Reforma do Estado (RERE). Salvador, Instituto Brasileiro de Direito Público, no. 10, junho/julho/agosto, 2007.

PEDRA, Adriano Sant'Ana. Reflexões sobre a teoria das cláusulas pétreas. In: Revista de Informação Legislativa. Brasília, ano 43, n. 172, out./dez. 2006.

PFERSMANN, Otto. Reformas Constitucionales Inconstitucionales: una perspectiva normativista. In: Revista Española de Derecho Constitucional. número 99, setembro-dezembro/2013. P. 17-60.

PORRAS, Javier Dorado. El debate sobre el control de Constitucionalidad en los Estados Unidos: una polémica sobre la interpretación constitucional. Madrid: Dykinson, 1997.

PRZEWORSKI, Adam. Ama a incerteza e serás democrático. In: Novos Estudos Cebrap, São Paulo, 9: 36-46, Jul. 1984.

RAMOS, Elival da Silva. A proteção aos direitos adquiridos no direito constitucional brasileiro. São Paulo: Saraiva, 2003. 
. Controle de constitucionalidade no Brasil: perspectivas de evolução. São Paulo: Saraiva, 2010.

. Ativismo Judicial: parâmetros dogmáticos. São Paulo: Saraiva, 2013.

RAWLS, John. O Liberalismo Político. 2. Edição. São Paulo: Ática, 2000.

. Uma teoria da justiça. São Paulo: Martins Fontes, 2000.

. Justiça como equidade: um reformulação. São Paulo: Martins Fontes, 2003.

ROCHA, Cármen Lúcia Antunes. Constituição e mudança constitucional: limites ao exercício do poder de reforma constitucional. Revista de informação legislativa. v. 30, n. 120 (out./dez. 1993).

RODRIGUEZ, José Rodrigo. Como decidem as cortes? Para uma crítica do Direito (brasileiro). Rio de Janeiro: Editora FGV, 2013.

RORTY, Richard. Objetivismo, relativismo e verdade - Escritos Filosóficos. Volume 1. Rio de Janeiro: Relume Dumará, 2002.

ROSENBERG, Gerald. The Road Taken: Robert A. Dahl's Decision-Making in a Democracy: The Supreme Court as a National Policy- Maker," 50 Emory Law Journal 613 (2001).

. Courting Disaster: Looking for Change in All the Wrong Places. 54 Drake Law Review 795 (2005).

ROSS, Alf. On Self-Reference and a Puzzle in Constitutional Law. Mind, 78, 1969, p. 1.

. Direito e Justiça. Bauru: Edipro, 2000.

ROZNAI, Yaniv. Unconstitutional Constitutional Amendments: A Study of the Nature and Limits of Constitutional Amendment Powers. Tese de Doutorado submetida ao Departamento de Direito da London School of Economics. Londres: 2014.

SAMPAIO, Nelson de Souza. Inconstitucionalidade de Emenda Constitucional. Revista de Direito Público. Ano XVI - no 67. Julho-Setembro de 1983. p. 5-19.

. Os limites da reforma constitucional. Revista Forense. Ano 59. OutubroNovembro-Dezembro de 1962. p. 34-38.

SARLET, Ingo Wolfgang. A eficácia dos direitos fundamentais: uma teoria geral dos direitos fundamentais na perspectiva constitucional. $10^{\underline{a}}$ ed. Porto Alegre: Livraria do Advogado, 2010. 
. Direitos Sociais - O problema de sua proteção contra o poder de reforma na Constituição de 1988. Revista de Direito Constitucional e Internacional. Vol. 46/2004. p. 42 - 73. Jan - Mar / 2004.

SARMENTO, Daniel. Direito Adquirido, Emenda Constitucional, Democracia e Justiça Social. In: Revista brasileira de Direito Público. Belo Horizonte, ano 3, no 9, p. 9-38, abr./jun. 2005.

. A ubiquidade constitucional: os dois lados da moeda. Revista de Direito do Estado n. 2, Rio de Janeiro: Renovar, 2006.

SARMENTO, Daniel; SOUZA NETO, Cláudio Pereira de. Os direitos fundamentais e o poder de reforma constitucional. In: Direitos fundamentais e jurisdição constitucional. CLÈVE, Clèmerson Merlin; FREIRE, Alexandre (org.). São Paulo: Editora Revista dos Tribunais, 2014.

SEIDMAN, Louis Michael. "The secret life of the political questions doctrine". In The John Marshall Law Review, no 37, 2004, pp. 441-480.

SILVA, José Afonso da. Curso de Direito Constitucional Positivo. São Paulo: Malheiros, 2014.

SILVA, Virgílio Afonso da. Ulisses, as sereias e o poder constituinte derivado: sobre a inconstitucionalidade da dupla revisão e da alteração no quorum de 3/5 para aprovação de emendas constitucionais. Revista de Direito Administrativo 226 (2001): 11-32.

. O Judiciário e as políticas públicas: entre transformação social e obstáculo à realização dos direitos sociais. In: Cláudio Pereira de Souza Neto \& Daniel Sarmento, Direitos sociais: fundamentação, judicialização e direitos sociais em espécies. Rio de Janeiro: Lumen Juris, 2008.

STERN, Klaus. Derecho del Estado de la Republica Federal Alemana. Centro de Estudios Constitucionales: Madrid, 1987.

STITH, Richard. "Unconstitutional Constitutional Amendments: The Extraordinary Power of Nepal's Supreme Court." American University International Law Review 11, ำ 1 (1996): 47-77.

STRECK, Lenio Luiz. Verdade e consenso: constituição, hermenêutica e teorias discursivas. 5 edição. São Paulo: Saraiva, 2014.

Hermenêutica jurídica $e(m)$ crise: uma exploração hermenêutica da construção do Direito. 11 edição. Porto Alegre: Livraria do Advogado Editora, 2014. 
SUSTEIN, Cass. After the rights revolution: reconceiving the regulatory state. Cambridge: Harvard University Press, 1990. . One Case at a Time. Cambridge: Harvard University Press, 2001. . A Constitution of many minds. Princeton University Press, 2009. . The partial Constitution. Cambridge: Harvard University Press, 2011. . ; VERMEULE, Adrian. Interpretation and Institutions. 101 Michigan Law Review 885, 2002-2003.

SWEET, Alec Stone; MATHEWS, Jud. Proportionality Balancing and Global Constitutionalism. Faculty Scholarship Series. 2008. Paper 14.

TAVARES, José Antonio Giusti. Sistemas eleitorais nas democracias contemporâneas; teoria, instituições, estratégia. Rio de Janeiro: Relume-Dumará, 1994.

TESEBELIS, George; Nard, Dominic. A Long Constitution is a (Positively) Bad Constitution: Evidence from OECD Countries. British Journal of Political Science. Volume 46 / Issue 02 / April 2016, pp 457-478.

TEUBNER, Gunther. The Project of Constitutional Sociology: Irritating Nation State Constitutionalism. In: Transnational Legal Theory. 4:1, 2013. P. 44-58.

THORNHILL, Chris. The global legal system and the procedural construction of constituent power. In: Global Constitucionalism Journal, Volume 5, Issue 3. November 2016. P. 405-442.

. The Sociological Origins of Global Law. In: FEBBRAJO, Alberto; CORSI, Giancarlo Corsi (org.). Sociology of Constitutions: A Paradoxical Perspective. Abingdon: Routledge; 2016. p. 99-124.

TSAKYRAKIS, Stavros. Proportionality: An assault on human rights?. International Journal of Constitutional Law. Volume 7, Issue 3, 1 July 2009. P. 468-493.

TUSHNET, Mark. Weak Courts, Strong Rights. New Jersey: Princeton University Press, 2008.

. Taking the constitution away from the Courts. Princeton: Princeton University Press, 1999.

VERMEULE, Adrian. Judging under uncertainty: an institutional theory of legal interpretation. Cambridge: Harvard University Press, 2006.

System Effects and the Constitution. 123 Harvard Law Review 4, 20092010. 
VESTING, Thomas. "Ende der Verfassung? Zur Notwendigkeit der Neubewertung der symbolischen Dimension der Verfassung in der Postmoderne. In: Thomas Vesting e Stefan Korioth (Orgs.) Der Eigenwert des Verfassungsrechts. Was bleibt von der Verfassung nach der Globalisierung?, Mohr Siebeck, Tübingen, 2011. P. 71-94.

VIEIRA, Oscar Vilhena. A Constituição e sua reserva de justiça (um ensaio sobre os limites materiais ao poder de reforma). São Paulo: Malheiros, 2009.

. Supremo Tribunal Federal - Jurisprudência Política. São Paulo: Malheiros, 2002.

VOIGT, Stefan. Explaining Constitutional Garrulity. International Review of Law and Economics. 2009. 29:290-303.

WALDRON, Jeremy. Law and Disagreement. $2^{2}$ edição. Oxford: Oxford, 2004. . The Core of the Case Against Judicial Review. In: The Yale Law Journal, n. 115 , p. 1346 a 1406. 